\title{
ONGs, expertise e o mercado do desenvolvimento sustentável: a certificação florestal na Amazônia brasileira
}

Marcelo Sampaio Carneiro - Professor Adjunto II do Departamento de Sociologia e Antropologia da Universidade Federal do Maranhão

\section{Resumo}

Este artigo analisa o processo de construção da certificação florestal - o selo do Forest Stewardship Council (FSC) como mecanismo para combater a exploração predatória dos recursos florestais na Amazônia brasileira. Nesta análise, ressalta-se o papel central desempenhado por algumas organizações não-governamentais (ONG) nesse processo e chama-se a atenção para o que se denomina "expertização" da questão florestal na Amazônia.

\begin{abstract}
This paper analizes the process of the construction of the Forestry certification - the label of the Forest Stewardship Council (FSC) - as a mechanism to combat the predatory exploitation of the natural resources from the Brazilian Amazonia. We analyze and emphasize the central role of some non-governmental organizations (NGO) on this process and call attention to what we are calling the expertization of the forestry question on the Amazonia.
\end{abstract}

\section{Palavras-chave}

Certificação florestal, exploração, recursos florestais, Amazônia.

\section{Keywords}

Forest certification, exploration, resources, Amazon. 
Marcelo Sampaio Carneiro

Uma das questões mais destacadas pelos estudos sobre a produção de políticas ambientais no mundo contemporâneo é a atuação das organizações não-governamentais (ONG). Tidas muitas vezes como agentes sem legitimidade para interferir nas grandes questões ecológicas globais (aquecimento global, debate sobre os transgênicos, futuro das florestas tropicais), uma vez que não dispõem da representatividade do Estado-nação ou estão muito distantes das necessidades das comunidades em nome das quais repetidas vezes se pronunciam (SMOUTS, 2001), essas organizações lançam mão de um variado cardápio de ações para enfrentar seus contestadores. Atuam como movimento de consumidores, utilizam intensamente (e de forma inovadora) a mídia (OLLITRAULT, 1999), estabelecem alianças com grupos sociais e recorrem crescentemente à ciência (BUTTEL; TAYLOR, 1994) para fazer valer seus pontos de vista.

Neste artigo apresentamos algumas facetas do processo de construção do mercado de madeiras certificadas na Amazônia brasileira, analisando o papel desempenhado por um grupo específico de ONGs (Amigos da Terra, Greenpeace, Instituto do Homem e Meio Ambiente da Amazônia (Imazon), Instituto de Manejo e Certificação Florestal e Agrícola (Imaflora), Fundação Floresta Tropical (FFT) $)^{1}$ ), identificadas como atores centrais na promoção da certificação florestal na Amazônia brasileira.

Conforme nossa interpretação procurará demonstrar, será por meio de iniciativas lideradas por essas ONGs ${ }^{2}$, atuando em faixas específicas de competência, que serão lançadas as bases para o fomento da certificação. Dessa forma, o esforço dessas organizações orientar-se-á para a construção de uma representação local favorável à idéia (e aos mecanismos) da certificação, defendida como instrumento capaz de intervir positivamente na mudança do padrão tradicional, e para a criação das condições materiais necessárias ao desenvolvimento dessa certificação, por meio de estímulos à sua adoção por empresas e empreendimentos comunitários localizados nos diversos estados da região.

\footnotetext{
${ }^{1}$ Atualmente denominada Instituto Floresta Tropical (IFT).

${ }^{2}$ Quando estivermos falando neste capítulo de ONGs, estaremos nos referindo às grandes ONGs ambientalistas internacionais com atuação na Amazônia (Amigos da Terra e Greenpeace), às ONGs de pesquisa (cf. classificação proposta por Buclet (2002, p. 268)) localizadas na Amazônia (Imazon e FFT) e ao Imaflora, uma ONG que atua como certificadora da rede Smartwood no Brasil.
} 
ONGs, expertisse e o mercado do desenvolvimento sustentável: a certificação florestal na Amazônia brasileira

Nesse processo destacamos duas dimensões que nos parecem essenciais: por um lado, o trabalho de crítica ao padrão tradicional da exploração florestal, realizado por meio de diversos mecanismos, com especial destaque para as pressões efetuadas por ONGs ambientalistas na cadeia global do comércio de madeiras (Global commodities chains na terminologia de Gereffi (1994)), de forma a estimular a adoção da certificação das empresas na Amazônia; por outro, a atuação na construção da legitimidade da certificação, de sua aceitação como mecanismo público ${ }^{3}$ de orientação do padrão da exploração florestal.

Enquanto a crítica será feita principalmente no plano da pressão internacional, nos principais mercados consumidores da Europa e dos Estados Unidos, a construção da legitimidade deve ser realizada no plano local, visando os vários atores da exploração florestal (empresários, agências estatais, intermediários e consumidores) e os segmentos da sociedade civil regional que participam mais ativamente dos debates sobre os rumos da questão ambiental na Amazônia.

Realizado em meio a uma intensa disputa midiática com setores do patronato florestal regional, o trabalho de proselitismo, de defesa da certificação implicará um grande esforço de divulgação, de promoção do conhecimento, do savoir-faire sobre a questão florestal e a construção de alianças com parte dos empresários do setor madeireiro, da burocracia estatal e com entidades de representação dos movimentos sociais da região (CARNEIRO, 2004). Trata-se, portanto, de um movimento i) no plano das idéias, que inclui a elaboração de representações sobre o que significa a questão florestal na Amazônia e a apresentação dos instrumentos necessários para enfrentá-la (florestas públicas de produção, certificação florestal, florestas familiares, safra legal) e ii) no processo de construção e viabilização de mecanismos institucionais de suporte ao desenvolvimento da certificação.

\footnotetext{
${ }^{3}$ Como argumentou Cochoy (2002), pretende-se construir a normalização de produtos como um mecanismo ao mesmo tempo imparcial e reconhecedor de cada uma das forças que atuam na definição da qualidade de um produto, no caso, o mercado, a firma e o Estado. Para esse autor, a normalização pretende realizar um triplo tour de force: "conseguir produzir referenciais que são ao mesmo tempo distintos dos interesses particulares de tal ou tal firma, estreitamente solidários dos interesses daqueles que participam do processo normativo, sem, entretanto, ser redutível às forças do mercado ou, pelo contrário, às decisões do legislador" (COCHOY, 2002, p. 79).
} 
Marcelo Sampaio Carneiro

Quando falamos de mecanismos institucionais ${ }^{4}$, estamos pensando em um conjunto de atividades que servem de suporte à exploração florestal, que surgiram na Amazônia a partir dos anos 90 e que apresentam uma clara interação com a certificação, seja por meio de incentivos à sua adoção pelos produtores - caso da difusão da tecnologia da exploração florestal de baixo impacto, de mecanismos de financiamento, da formação de profissionais para a certificação (auditores, técnicos das empresas, etc.) -, seja no plano do mercado consumidor por meio da promoção dos produtos oriundos de florestas certificadas e mesmo da organização da seção brasileira do grupo de compradores de madeira certificadas.

As diversas iniciativas que serão detalhadas situam-se, portanto, nestes dois planos: o da elaboração de representações sobre o destino dos recursos florestais na Amazônia (e, por conseguinte, da própria Amazônia) e o da construção de iniciativas para interferir nesse destino.

Em nossa tese de doutorado, detalhamos o conjunto de ações que consideramos centrais na promoção da certificação florestal na Amazônia (CARNEIRO, 2004). Para o presente artigo selecionamos três processos que mostram, de forma exemplar, a atuação das ONGs acima citadas na promoção da certificação: i) a elaboração do padrão de certificação do FSC para o manejo em florestas de terra firme na Amazônia brasileira, ii) o desenvolvimento e a difusão da tecnologia da exploração florestal de impacto reduzido (EIR) e iii) a formação e a atuação do Grupo de Compradores de Madeira Certificada (GCMC).

Após descrevermos a atuação dessas organizações no processo de certificação, fechamos nossa abordagem com uma análise das relações estabelecidas entre essas ONGs, do papel desempenhado por instituições da cooperação internacional no processo de construção da certificação florestal e sublinhamos aquilo que nos parece ser a dimensão central desse processo: a expertização ${ }^{5}$ da questão florestal na Amazônia.

\footnotetext{
${ }^{4}$ Seguimos o proposto por Bass (1998, p. 7), que identificou como condições preliminares para o bom funcionamento da certificação os seguintes aspectos: i) um mercado sensível às questões ambientais e/ou sociais; ii) um sistema apropriado de manejo florestal; iii) um quadro normativo forte o suficiente para apoiar esse manejo; iv) uma comunicação efetiva com as partes interessadas.

${ }^{5}$ Por "expertização" entendemos o peso crescente que a mobilização do conhecimento técnico para fins de decisão (ROQUEPLO, 1997, p. 15) tem assumido na discussão de questões centrais sobre o desenvolvimento da Amazônia. Esse conhecimento pode ser detido por um profissional ou por uma instituição, cujo domínio técnico é socialmente reconhecido e validado. A expertise rompe, portanto, com a distinção weberiana entre o intelectual e o político, associando conhecimento e julgamento de valor num processo decisório (KALAORA, 1999, p. 513).
} 
ONGs, expertisse e o mercado do desenvolvimento sustentável: a certificação florestal na Amazônia brasileira

\section{0 processo de elaboração do padrão de certificação da operação de manejo na floresta amazônica de terra firme}

O padrão de certificação é o documento com os princípios e critérios (P G C) do bom manejo florestal do FSC a ser utilizado pelas certificadoras para avaliar determinada formação florestal. Esse padrão é elaborado pelas iniciativas nacionais do FSC, a partir dos P \& C definidos internacionalmente. Para tanto, a iniciativa nacional deve identificar e mobilizar as partes interessadas (stakeholders) na definição do referido padrão e mobilizá-las para discuti-lo e aprová-lo.

O processo de desenvolvimento do padrão para manejo de florestas de terra firme começou em 1997 e foi finalizado em $2001^{6}$. Para conduzir o processo de elaboração do padrão, o grupo de trabalho que implantou o FSC no Brasil (GT-FSC Brasil) formou um subgrupo de trabalho, composto por seis pessoas, três representando as câmaras constitutivas do FSC e três especialistas, seguindo o parâmetro da divisão tripartite (câmara ambiental, câmara social e câmara econômica) que marca a organização do FSC.

Pelo primeiro critério, compunham o subgrupo de trabalho: um representante do Grupo de Trabalho Amazônico (GTA) - câmara social do FSC-Brasil -, um do Imazon - câmara ambiental - e outro da Associação das Indústrias Exportadoras de Madeira do Estado do Pará (AIMEX) - câmara econômica. Os especialistas convidados foram: Rita de Cássia Mesquita, bióloga, pesquisadora do Instituto Nacional de Pesquisas da Amazônia (INPA), Virgilio Viana, engenheiro florestal, professor da Escola Superior de Agricultura "Luiz de Queiroz" (ESALQ) da Universidade de São Paulo (USP), e José Natalino da Silva, pesquisador da Empresa Brasileira de Pesquisa Agropecuária (Embrapa), também engenheiro florestal.

O trabalho coordenado por esse subgrupo envolveu diversas etapas, seguindo um ritual de elaboração de cinco versões provisórias, todas submetidas à apreciação do GT-FSC Brasil, e de mecanismos de consulta mais amplos (envio por correio a partes interessadas e workshops), conforme mostra o quadro a seguir.

\footnotetext{
${ }^{6}$ Sobre o movimento de constituição do FSC no Brasil ver Faillace (2001) e o documento do Greenpeace- Brasil (2003, p. 12), que apontam quatro momentos centrais nesse movimento: i) o processo de consultas que antecede a assembléia de fundação do FSC, ii) o da formação de um GT provisório pós-assembléia, iii) o da indicação de uma pessoa de contato do FSC Internacional no Brasil e iv) a constituição do Conselho Brasileiro de Manejo Florestal (CBMF).
} 
Marcelo Sampaio Carneiro

\begin{tabular}{|l|l|}
\hline Versão 1 & \\
\hline 1.0 & Elaborada por consultora. \\
\hline 1.1 & Analisada no Subgrupo de Trabalho do GT Floresta Amazônica (SGT-FA). \\
\hline 1.2 & Analisada pelo GT FSC-Brasil e liberada para consulta ampla. \\
\hline Versão 2 & \\
\hline 2.0 & Aprovada pelo GT e SGT-FA e submetida a consulta ampla. \\
\hline 2.1 & Após incorporação das sugestões da consulta ampla, analisada pelo SGT-FA. \\
\hline 2.2 & Analisada pelo GT FSC-Brasil e liberada para Workshop I. \\
\hline Versão 3 & \\
\hline 3.0 & Submetida ao Workshop I. \\
\hline 3.1 & Após receber contribuições do W1, analisada pelo SGT-FA. \\
\hline 3.2 & Analisada pelo GT FSC-Brasil e liberada para teste de campo. \\
\hline Versão 4 & \\
\hline 4.0 & Submetida ao teste de campo (TC). \\
\hline 4.1 & Após receber contribuição do TC, analisada pelo SGT-FA. \\
\hline 4.2 & Analisada pelo GT e liberada para o workshop de harmonização. \\
\hline 4.3 & Submetida ao workshop de harmonização. \\
\hline Versão 5 & \\
\hline 5.0 & Analisada pelo SGT-FA. \\
\hline 5.1 & Analisada pelo GT FSC-Brasil e liberada para o Workshop II. \\
\hline 5.2 & Submetida ao Workshop II. \\
\hline 5.3 & Analisada pelo SGT-FA. \\
\hline 5.4 & $\begin{array}{l}\text { Analisada pelo GT FSC -Brasil, que realiza mais uma consulta ampla, faz a } \\
\text { incorporação das sugestões da consulta e envia o Padrão à secretaria geral do } \\
\text { FSC para sua homologação na reunião do conselho de diretores. }\end{array}$ \\
\hline
\end{tabular}

Quadro 1: Fases da elaboração do padrão de certificação para floresta de terra firme da Amazônia Brasileira.

Fonte: Dados coligidos na Secretaria do FSC-Brasil.

Como aparece no quadro, a elaboração dos padrões passa por um longo caminho: parte-se de um documento original elaborado por um especialista do setor florestal, que é submetido a diversos mecanismos de consultas (as chamadas "partes interessadas") e finalmente enviado para homologação no FSC Internacional. Para nossos objetivos, interessa principalmente a identificação dos participantes quando se alarga o processo de construção do documento, saindo do campo restrito da expertise florestal para receber a crítica das "partes interessadas" na construção das normas da certificação.

Um primeiro momento para observar essa participação é o da composição do subgrupo de trabalho constituído para conduzir o processo de construção do padrão de terra firme. A presença de organizações como AIMEX e GTA no subgrupo de trabalho sugere uma boa representatividade para a condução do processo, uma vez que essas entidades possuem forte penetração em parcelas significativas, 
ONGs, expertisse e o mercado do desenvolvimento sustentável: a certificação florestal na Amazônia brasileira

respectivamente, do patronato florestal e dos movimentos sociais na Amazônia.

Entretanto, será por meio análise das entidades presentes nos dois workshops que poderemos identificar o tipo de capilaridade que a construção dos padrões conseguiu alcançar . O primeiro workshop foi realizado em Belém (PA), nos dias 1. ${ }^{\circ}$ e 2 de dezembro de 1998, enquanto o segundo aconteceu em Manaus, nos dias 8 e 9 de fevereiro de 2000.

O objetivo do primeiro encontro foi promover a discussão com representantes das três câmaras (social, ambiental e econômica) sobre a versão 3.0 do documento, para depois encaminhá-lo ao teste de campo. Participaram do workshop trinta e sete (37) pessoas, representando vinte e seis (26) entidades, na sua maior parte representações de instituições estatais - com destaque para institutos de pesquisa (INPA e Embrapa) e instituições de ensino superior - e de organizações não-governamentais, conforme indicado no gráfico a seguir (Gráfico 1).

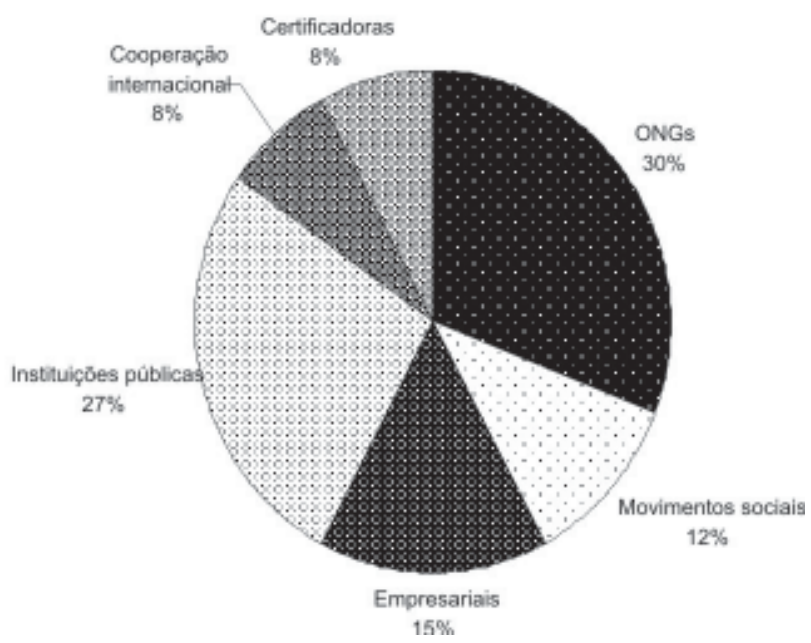

Gráfico 1: Participação de representantes por tipo de entidade no Workshop I.

Nesse primeiro encontro, fica evidente a pequena participação de

\footnotetext{
${ }^{7}$ Na pesquisa que realizamos na Secretaria do FSC-Brasil em Brasília, não foi possível identificar o público atingido nas duas consultas amplas realizadas no processo de elaboração dos padrões, mas conseguimos levantar todos os participantes nos dois workshops.
} 


\section{Marcelo Sampaio Carneiro}

representantes dos movimentos sociais ${ }^{8}$ e dos empresários do setor florestal ${ }^{9}$, com o predomínio de representantes de ONGs e instituições estatais. Trata-se de um evento com perfil marcadamente técnico, com o predomínio de profissionais com diploma de nível superior (34 de 37 presentes), dos quais pelo menos quinze (15) com curso de pósgraduação stricto sensu (10 mestres e 5 doutores) ${ }^{10}$, predominando a formação nas áreas de Engenharia Florestal (55\% do total) e de Agronomia (21\%).

O predomínio de profissionais de nível superior deve-se à presença de pesquisadores de instituições universitárias, da Embrapa e do INPA, de representantes das certificadoras (Imaflora e Scientific Certification System (SCS)) e de técnicos das ONGs, uma vez que esse último grupo está representado principalmente por entidades ambientalistas (WWF, Amigos da Terra) ou de pesquisa ${ }^{11}$ (Imazon e FFT), que têm na atividade de expertise florestal um dos principais focos de sua atuação.

No período que seguiu o primeiro workshop, o documento do padrão foi submetido a um teste de campo, realizado com a participação das certificadoras com atuação no Brasil (SCS, Société Générale de Surveillance (SGS) e Rede Smartwood), e a uma oficina de harmonização, com representantes de outras iniciativas de certificação da Bacia Amazônica (Peru, Bolívia e Colômbia). Após esses dois eventos, e sempre passando pelo crivo da análise do subgrupo de trabalho e do Grupo de Trabalho FSC-Brasil, o documento foi submetido a mais um workshop e a uma consulta pública, para depois ser enviado ao FSC Internacional para homologação.

O segundo workshop para elaboração do padrão foi realizado em Manaus (AM), nos dias 8 e 9 de fevereiro de 2000, contando com um número bem maior de participantes (65 pessoas representando 47 entidades), quando comparado com o do primeiro encontro, sem, contudo, apresentar qualquer variação mais significativa na divisão percentual dos grupos de entidades (ONGs, empresas, movimentos

\footnotetext{
${ }^{8}$ Participaram representantes dos seguintes movimentos: Organização dos Seringueiros de Rondônia (OSR), Coordenação das Organizações Indígenas da Amazônia Brasileira (COIAB) e da Federação Internacional de Trabalhadores da Construção e da Madeira (FITCM).

${ }^{9}$ Representando a Gethal Amazonas SA, a Nordisk Timber, a Jari Florestal e a Associação das Indústrias Madeireiras de Santarém (ASSIMAS).

${ }^{10}$ Cf. pesquisa realizada no banco de currículos da Plataforma Lattes.

${ }^{11}$ ONGs de pesquisa são aquelas cujas atividades "giram em torno da produção de análises científicas e da proposição de modelos de gestão sustentável dos recursos naturais" (BUCLET, 2002, p. 268).
} 
ONGS, expertisse e 0 mercado do desenvolvimento sustentável: a certificação florestal na Amazônia brasileira

sociais e instituições estatais) presentes no evento, como mostra o Gráfico 2 .

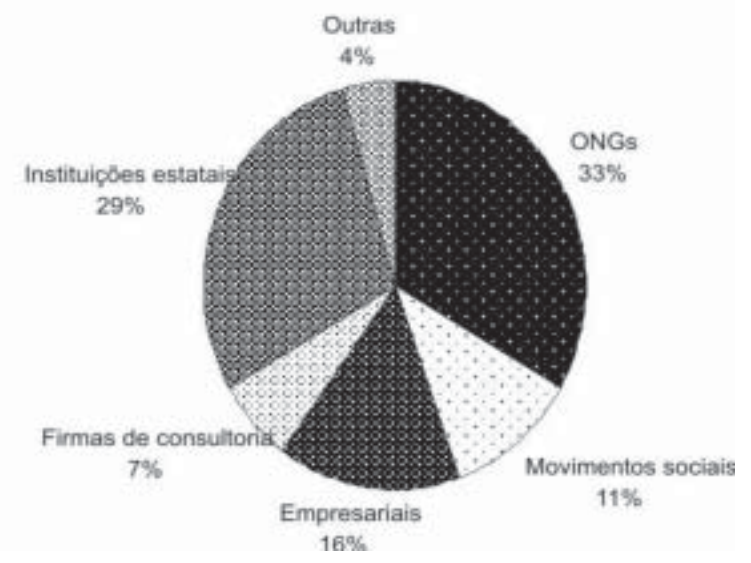

Gráfico 2: Participação de representantes por tipo de entidade no Workshop II.

Para compreender o tipo de representação presente nesse segundo encontro, é necessário descer à composição interna de cada grupo de entidades acima apresentado. Como pode ser observado no Quadro 2, a ampliação do número de entidades será mais forte no segmento das ONGs e das instituições estatais, ocorrendo ainda um pequeno aumento na representação de entidades dos movimentos sociais e do segmento empresarial. 
Marcelo Sampaio Carneiro

\begin{tabular}{|c|c|c|c|}
\hline & Workshop I & \multicolumn{2}{|l|}{ Workshop II } \\
\hline Empresas & $\begin{array}{l}\text { Gethal Amazonas } \\
\text { Nordisk Timber } \\
\text { Jari Florestal } \\
\text { ASSIMAS }\end{array}$ & $\begin{array}{l}\text { Sindimad/MT } \\
\text { Sindiserpa/PA } \\
\text { Sindilam/MT } \\
\text { Sindimad/AC }\end{array}$ & $\begin{array}{l}\text { Nordisk Timber } \\
\text { Amcel } \\
\text { Precious Wood }\end{array}$ \\
\hline ONGs & $\begin{array}{l}\text { Imazon } \\
\text { FFT } \\
\text { WWF } \\
\text { Amigos da Terra } \\
\text { Fórum Carajás } \\
\text { Ecoporé } \\
\text { GDA }\end{array}$ & $\begin{array}{l}\text { Imazon } \\
\text { WWF } \\
\text { Amigos da Terra } \\
\text { Fórum Carajás } \\
\text { FASE } \\
\text { GTNA } \\
\text { CPT/AM } \\
\text { CPT/AP } \\
\end{array}$ & $\begin{array}{l}\text { ISA } \\
\text { AVIVE } \\
\text { Greenpeace } \\
\text { ICV } \\
\text { Projeto Saúde e Alegria } \\
\text { Fórum de ONGs de Rondônia } \\
\text { Pastoral Indigenista }\end{array}$ \\
\hline $\begin{array}{l}\text { Movimentos } \\
\text { sociais }\end{array}$ & $\begin{array}{l}\text { COIAB } \\
\text { OSR } \\
\text { FITCM }\end{array}$ & $\begin{array}{l}\text { CNS } \\
\text { CUT } \\
\text { CUNPIR } \\
\text { GTA } \\
\text { Sind. dos Trabalh }\end{array}$ & stria da Madeira de Itacoatiara \\
\hline $\begin{array}{l}\text { Instituições } \\
\text { estatais }\end{array}$ & $\begin{array}{l}\text { Inpa } \\
\text { Embrapa } \\
\text { ESALQ/USP } \\
\text { UFSC } \\
\text { Lasat/UFPA } \\
\text { Ipaam } \\
\text { Ibama } \\
\end{array}$ & \begin{tabular}{|l} 
Inpa \\
Embrapa \\
UFMS \\
UFMT \\
UFRRJ \\
FCAP \\
FUA \\
\end{tabular} & $\begin{array}{l}\text { Fundacentro/MTb } \\
\text { Escola Agrotécnica de Manaus } \\
\text { Secretaria de Florestas/AC } \\
\text { SEAF/AP } \\
\text { IMAC } \\
\text { ProManejo/Ibama }\end{array}$ \\
\hline Outras & $\begin{array}{l}\text { Imaflora } \\
\text { SCS } \\
\text { Cifor } \\
\text { FNV (Holanda) }\end{array}$ & $\begin{array}{l}\text { APEF/MT } \\
\text { Imaflora }\end{array}$ & $\begin{array}{l}\text { Ambiental Consultoria } \\
\text { GSZ Consultoria } \\
\text { ASSEFLORA Consultoria }\end{array}$ \\
\hline
\end{tabular}

Quadro 2: Lista de entidades presentes nos workshops para elaboração dos padrões de certificação para floresta amazônica de terra firme.

Fonte: Dados coligidos na Secretaria do FSC-Brasil.

A mudança mais importante no grupo das ONGs é o aumento da participação das ONGs que podem ser classificadas como militantes ${ }^{12}$, que passam de uma entidade presente no workshop I para quatro (Comissão Pastoral da Terra (CPT)/AP, CPT/AM, Pastoral Indigenista e Federação de Órgãos para Assistência Social e Educacional (FASE)) nesse segundo encontro. Vale ressaltar também a participação de algumas ONGs ambientalistas e socioambientalistas - ausentes do primeiro encontro - como o Greenpeace, o Instituto Socioambiental e o Projeto Saúde e Alegria.

Outra ampliação importante ocorreu no campo das instituições estatais, com o aumento da presença de instituições federais de ensino

12 Essas ONGs "são geralmente voltadas para uma causa bem definida: mulheres, negros, direitos humanos, cultura, excluídos, organização popular, etc. Elas assumem o fato de terem uma função política. Os membros dessas ONGs são majoritariamente de esquerda e militantes do Partido dos Trabalhadores" (BUCLET, 2002, p. 268). 
ONGs, expertisse e o mercado do desenvolvimento sustentável: a certificação florestal na Amazônia brasileira

superior da Amazônia (Universidade Federal de Mato Grosso (UFMT), Faculdade de Ciências Agrárias do Pará (FCAP) e Fundação Universidade do Amazonas (FUA)) e de secretarias estaduais de fomento ao extrativismo (SEAF/AP e Secretaria de Florestas/AC). No que concerne aos movimentos sociais, houve uma pequena ampliação do número de entidades (3 para 5), com a presença da maior central sindical brasileira (Central Única dos Trabalhadores (CUT)) e da maior rede de entidades da Amazônia (GTA).

Como foi visto, os segmentos que tiveram maior presença nos dois encontros foi o das ONGs e das instituições estatais, o que denota, por um lado, o papel das ONGs de condutores do processo de certificação na Amazônia - principalmente as ambientalistas - e, por outro, o forte apelo técnico da discussão, exemplificado no recurso a experts de instituições de pesquisa (Inpa e Embrapa) e de universidades para a elaboração do padrão de certificação.

\section{A FORMAÇÃO DA BASE TÉCNICA PARA A EXPANSÃO DA CERTIFICAÇÃ̃O: O TRABALHO DO IMAZON E DA FUNDAÇÃO FLORESTA TROPICAL}

A certificação do FSC trabalha com a noção de "bom manejo florestal", expressão empregada para designar operações que trabalham segundo padrões aceitáveis de manejo florestal. Segundo Viana (2002, p. 19-20), essa expressão "nasceu da necessidade de definir critérios e indicadores objetivos que fossem passíveis de verificação no campo", de forma a garantir que uma unidade de manejo florestal com performance (ambiental, social e econômica) superior à das demais do seu entorno regional pudesse ser avaliada e aprovada. Na prática, contudo, essa noção tem correspondido à utilização de técnicas de exploração florestal de impacto reduzido (ou exploração de baixo impacto), na forma que esse 'modelo' de gestão florestal assume, em cada região específica onde tem sido adotado (Anexo A).

Como diversos analistas registraram (BLATE; PUTZ; ZWEEDE, 2001; DYKSTRA, 2001; HINRICHS; RUSLIM, 2001), um dos principais entraves ao desenvolvimento da exploração de baixo impacto tem sido a ausência da geração de conhecimento local sobre a aplicação da EIR e de pessoal qualificado para executá-la. No caso da Amazônia brasileira, essas deficiências começaram a ser supridas a partir do início dos anos 90, com as pesquisas levadas a cabo pelo Imazon e pela constituição de centros de treinamento e de transferência de tecnologia da Fundação 


\section{Marcelo Sampaio Carneiro}

Floresta Tropical $^{13}$.

Como ressaltou Souza (1999, p. 71-72), o elemento inovador do trabalho dessas instituições - que utilizarão as pesquisas já realizadas (pela Embrapa, pelo Inpa e pela pela Sudam) ou em curso na região está na dimensão integrada que elas conferem ao tema do manejo florestal, isto é, agregam preocupações de natureza econômica e política ao componente ecológico e à aplicação de seus trabalhos, que sempre terão como norte as condições de sua viabilização por parte das empresas locais.

Esse caráter aplicado do conhecimento produzido pode ser considerado como uma das marcas da atuação do Imazon, ONG de pesquisa fundada em 1990 (BUCLET, 2002, p. 7), como um mito fundador, recorrentemente ressaltado em suas publicações. No relatório comemorativo dos dez anos de suas atividades, o diretor-executivo da entidade ressaltou esse aspecto na introdução:

Nesta época (final dos anos 80), o ecólogo Christopher Uhl, que estava realizando pesquisas no leste do Pará, preocupava-se com o pouco entendimento e a rara documentação das transformações na região. Ele compreendia que a escassez de pesquisas sobre essas transformações enfraquecia o debate sobre os problemas e alternativas para a Amazônia. [...]. Entretanto, Uhl não se limitou apenas a identificar problemas. Ele viu em sua preocupação uma oportunidade para servir a região. Assim, juntou-se a outros interessados e criou um instituto de pesquisa com o objetivo de documentar e buscar soluções para os problemas relacionados ao uso dos recursos naturais na Amazônia (IMAZON, 2001, p. 7).

As primeiras pesquisas do Imazon focalizaram os usos dos recursos naturais em regiões de forte atividade madeireira, com um olhar especialmente voltado para a análise das técnicas de extração de madeira e das práticas silviculturais pós-exploratórias. Essas pesquisas foram realizadas no município de Paragominas (PA), numa área adquirida de

${ }^{13}$ A Fundação Floresta Tropical, ONG com sede em Belém, fundada em 1994, surgiu como resultado das pesquisas sobre exploração de impacto reduzido realizadas na Amazônia Oriental pela entidade norte-americana Tropical Forest Foundation em parceria com o Imazon. 
ONGs, expertisse e o mercado do desenvolvimento sustentável: a certificação florestal na Amazônia brasileira

uma serraria local (UHL et al., 1997, p. 20).

Um dos primeiros trabalhos da entidade sobre a extração madeireira procurou demonstrar as vantagens da introdução de algumas medidas do repertório de técnicas preconizado pelo método da EIR ${ }^{14}$, quando comparadas com a exploração convencional. A conclusão do estudo apontou o fato de que a introdução de técnicas simples de manejo poderia levar a um aumento substancial do volume de madeira comercial e de que os lucros das empresas madeireiras da região eram suficientes para arcar com os custos da realização do manejo florestal (VERÍSSIMO et al., 1996, p. 31-33).

Em 1997 o Imazon publicou um outro trabalho, contendo uma síntese do aprendizado das pesquisas realizadas sobre os diversos tipos de exploração madeireira na Amazônia e indicando as medidas julgadas necessárias para a modificação do padrão vigente na região. Essas medidas são agrupadas em três eixos: i) a difusão de tecnologia apropriada, ii) o aperfeiçoamento (simplificação) da legislação florestal e iii) o zoneamento florestal (UHL et al., 1997). Ainda nessa publicação, o instituto reafirma a dimensão aplicada do seu trabalho:

Os resultados desses estudos sobre manejo florestal estão sendo publicados em periódicos convencionais de pesquisa [...] Contudo, os mais interessados receptores dessa informação são os atores do setor florestal e os extratores. Por isso, os resultados de nossas pesquisas foram compilados num manual florestal especificamente direcionado para os madeireiros (IMAZON, 2001, p. 23).

Embora essa atuação do Imazon na difusão das técnicas da EIR tenha sido importante, ela apresentava limitações evidentes, visto que a adoção pelas empresas das indicações geradas pelas pesquisas demandaria um esforço mais consistente do que a publicação de um manual de práticas florestais ${ }^{15}$, exigindo, como veremos a seguir, um programa de formação de profissionais do setor, tarefa que foi assumida

\footnotetext{
${ }^{14}$ São elas: i) o levantamento pré-exploratório, ii) o corte de cipós e iii) o anelamento/desbaste de espécies sem valor econômico.

${ }^{15}$ Como afirmam May e Pastuk (1996), os esforços do Imazon no campo da difusão de novas tecnologias do manejo florestal foram além da publicação do manual, incluindo a produção de um vídeo (Floresta para Sempre) e a realização de demonstração de campo das técnicas de extração de madeira para diretores de várias empresas madeireiras da região de Paragominas.
} 
Marcelo Sampaio Carneiro

e executada pela FFT.

A Fundação Floresta Tropical começou a operar na Amazônia em 1994, trabalhando a partir de uma base de pesquisa e treinamento estabelecida em Paragominas, numa área de um mil hectares cedida pela empresa Cikel Brasil Verde SA. A entidade realiza a "promoção e a disseminação do manejo sustentável das florestas tropicais", com uma ênfase especial "na implantação de modelos de manejo florestal e exploração de impacto reduzido" junto a produtores, instituições governamentais e não governamentais do setor florestal (FFT, 2000).

O marco do desenvolvimento do programa de formação foi a realização, em 1995, do "I Curso Intensivo de Exploração de Baixo Impacto em Florestas Naturais da Amazônia", organizado em parceria com o Imazon e o Imaflora. A partir de então, os cursos têm sido conduzidos somente pela Fundação, que ampliou seu raio de atuação, estabelecendo outros locais de treinamento, nos Estados do Mato Grosso (nos municípios de Cláudia e Marcelândia) e do Pará (nos municípios de Portel e Santarém) (FFT, 2000, p. 2).

A estratégia de difusão da tecnologia de EIR da FFT inclui um variado leque de instrumentos: os cursos já citados, que são realizados nas áreas da Fundação; treinamentos in situ, com a demonstração da tecnologia da EIR diretamente nas áreas das empresas; estágios para estudantes de nível médio e superior; dias de campo, instrumento tradicional da prática extensionista para processos de transferência de tecnologia, além da elaboração e da divulgação de publicações e vídeos sobre o tema.

Vale dizer também que boa parte dessas atividades de extensão foi e está sendo realizada com o apoio de recursos oriundos da cooperação internacional. Assim, no período para o qual dispomos de dados sobre a atuação da Fundação (de 1996 a 2000), dois financiamentos garantiram a realização dos treinamentos e a presença do público participante: de 1996 a 1999, o Projeto PD 45/97 VER.1(F), da Organização Internacional de Madeiras Tropicais (ITTO), e, a partir de 2000, o Projeto "Modelo de Manejo Florestal e Exploração de Impacto Reduzido e Treinamento na Região de Paragominas", financiado pelo ProManejo, pela agência americana de cooperação (USAID) e pela Caterpillar do Brasil Ltda ${ }^{16}$.

Uma forma de verificar a eficácia da atuação da FFT e de medir a penetração da difusão das técnicas de EIR é examinar o público que ${ }^{16}$ Esse projeto e o da realização de um vídeo sobre as técnicas da EIR (também apoiado pelo
ProManejo) foram apresentados pela FFT em conjunto com a empresa Cikel Brasil Verde S.A. 
ONGs, expertisse e o mercado do desenvolvimento sustentável: a certificação florestal na Amazônia brasileira

participa dos seus treinamentos. No caso dos cursos realizados nessa primeira fase, que corresponde ao período de 1996 e $1999^{17}$, o grupo que apresentou maior número de participantes foi o de alunos de instituições de ensino médio, da Escola Agrotécnica de Manaus e da Escola Agroindustrial Juscelino Kubitscheck de Oliveira (com 43\% do total), vindo em seguida técnicos de instituições estaduais de meio ambiente, técnicos de instituições de pesquisa não-governamentais e representantes da indústria madeireira (Gráfico 3) (FFT, 2000, 2001).

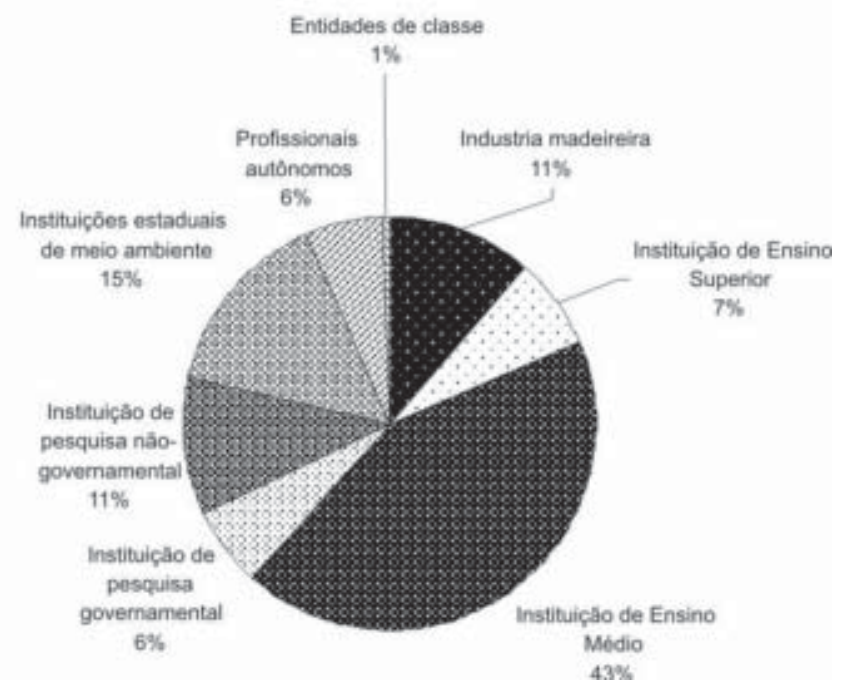

Gráfico 3: Perfil dos Participantes nos Cursos da FFT (1996 a 1999).

Como essa demanda é induzida, isto é, direcionada para o públicoalvo dos projetos que financiam a atividade de formação, o número privilegiado de técnicos participantes dos cursos, estudantes de nível médio e profissionais de instituições estaduais de meio ambiente está relacionado com o objetivo dos projetos (a promoção da EIR), que têm nesse público de gestores da atividade florestal na Amazônia e de (futuros) profissionais de campo um foco privilegiado.

A presença relevante de representantes da indústria madeireira entre os atingidos pelos cursos é um dado quase óbvio, haja vista a

${ }^{17}$ Participaram dos cursos 195 pessoas, das quais 18 oriundas de outros países (FFT, 2000, p. 10). Para a elaboração do gráfico consideramos apenas o público brasileiro. 


\section{Marcelo Sampaio Carneiro}

importância do segmento para a adoção da $\operatorname{EIR}^{18}$, embora deva ser ressaltado, como veremos mais abaixo, que esse público também é atingido por outros instrumentos de difusão da Fundação, casos do treinamento in situ e dos dias de campo.

O leque de cursos oferecidos pela Fundação amplia-se a partir de 2000, na segunda fase, que é apoiada pelo projeto financiado por ProManejo, USAID e Caterpillar. Nesse momento teremos a oferta de cursos que podem ser considerados como extremamente específicos ${ }^{19}$, mas também aqueles mais abrangentes, como o de "Educação em Manejo Florestal para Tomadores de Decisão" (FFT, 2001, p. 4). As informações sobre o primeiro ano do projeto indicam que o perfil dos participantes varia de acordo com a natureza dos cursos. Assim, nos cursos técnicos, o público mais importante é o dos trabalhadores da indústria; no curso de "Educação em Manejo Florestal", a dominância será de representantes do governo, enquanto no curso de "Gerenciamento de Manejo Florestal-EIR" os representantes de ONGs serão a maioria, provavelmente sob o influxo do apoio do ProManejo ao desenvolvimento de projetos de manejo florestal comunitário.

Embora todas essas atividades desenvolvidas pela FFT estejam intimamente relacionadas com o fomento da certificação, uma merece destaque especial: o treinamento in situ - realizado diretamente nas áreas das empresas interessadas -, uma vez que três das quatro empresas que tiveram esse tipo de treinamento obtiveram a certificação do FSC: a Gethal, a Cikel e a Juruá (FFT, 2001, p. 7). Dados mais recentes, do final de 2003, confirmam essa interação entre as atividades da FFT e o movimento de certificação florestal na Amazônia:

"(...) Natalino Silva, um pesquisador florestal bem conhecido [...] nos informou que a formação

\footnotetext{
${ }^{18}$ A importância desse subsídio foi citada como um dos principais fatores no processo de difusão da EIR na Amazônia brasileira: "No Brasil o mais importante motor da EIR consiste na sua maior eficácia operacional e nas economias de custo que daí resultam. Convém ressaltar, todavia, que a maior parte das empresas que colocaram em operação a EIR só foram convencidas de suas vantagens após terem recebido uma assistência técnica e, em certos casos, subvenções para a formação de seus trabalhadores" (BLATE; PUTZ; ZWEEDE, 2001, p. 9). Machfudh et al. (2001, p. 11) argumentam de forma similar, ao analisar a necessidade do apoio internacional para a fase inicial da implantação da EIR na Indonésia.

${ }^{19}$ Curso de técnicas de identificação de árvores, aplicadas em manejo florestal de impacto reduzido (MFIR), curso de técnicas de arraste, aplicadas em MFIR, curso de técnicas em construção de infra-estrutura, aplicadas em MFIR, e curso de técnicas de corte, aplicadas em MFIR (FFT, 2001, p. 4).
} 
ONGs, expertisse e o mercado do desenvolvimento sustentável: a certificação florestal na Amazônia brasileira

oferecida pelo projeto [da ITTO] é de fato considerada como a norma que satisfaz integralmente as condições da EIR relativas à certificação. Ele sublinhou que, em julho de 2003, dez empresas florestais da Amazônia brasileira [...] foram certificadas pelo FSC. Nove dessas empresas, representando 80\% da superfície total certificada, tiveram recurso à formação em EIR oferecida pelo projeto (DYKSTRA; ELIAS, 2003, p. 4).

Outro resultado que pode ser imputado à atuação da FFT e que deve ter repercussões na exploração florestal na Amazônia é a criação de novas instituições para realizar o treinamento em manejo florestal e exploração de impacto reduzido, como a Escola de Floresta em Santa Carmem (MT), o Centro de Referência da Mil Madeireira em Itacoatiara (AM) e o Centro de Treinamento Promatec em Sena Madureira (AC), iniciativas apoiadas pelo ProManejo, que são "exemplos do processo de disseminação e capacitação das práticas de impacto reduzido provenientes do projeto" da FFT, realizado na área cedida pela Cikel (FLORESTA..., 2002, p. 4).

\section{Construindo a demanda interna para a madeira certificada: a formação e o desenvolvimento do grupo de compradores de produtos certificados no Brasil.}

O grupo de compradores de madeira certificada ${ }^{20}$, da seção brasileira da rede global de comércio e floresta, foi fundado em abril de 2000, contando originalmente com 38 membros ${ }^{21}$. Como será demonstrado em seguida, sua constituição foi resultado da atuação de três ONGs, Imaflora, Imazon e Amigos da Terra - Programa Amazônia, por meio da parceria denominada "Aliança para o consumo

\footnotetext{
${ }^{20}$ Posteriormente a entidade teve seu nome alterado para Grupo de Compradores de Produtos Florestais Certificados. Como sua atuação está voltada principalmente para a promoção do mercado de madeiras, continuaremos utilizando sua denominação original ao longo do trabalho.

${ }^{21}$ Segundo seu Estatuto, o Grupo de Compradores tem como metas: realizar atividades de informação sobre o consumo sustentável de produtos florestais, viabilizar atividades de assistência técnica, promover articulação e mobilização, encontros e conferências para o incentivo de atividades que sejam social e ambientalmente corretas.
} 
Marcelo Sampaio Carneiro

sustentável", cabendo a essa última um papel mais direto na condução do grupo.

A necessidade do desenvolvimento de iniciativas para tentar organizar uma atuação no mercado interno de madeiras no Brasil é uma preocupação que antecede a criação do grupo de compradores. Dessarte, já em 1997, na seção "Preparando esquemas de certificação" do trabalho Garimpagem Florestal: relatório atualizado sobre a extração ilegal de madeira na Amazônia brasileira, a ONG Amigos da Terra esboçava um programa de atuação nesse sentido:

(..) - o consumidor brasileiro deveria ser estimulado a se tornar mais consciente e reivindicar garantias aos fornecedores, através da certificação, de que as cadeiras, os lápis, a madeira para revestir pisos e tetos e o papel que está comprando contribuem para proteger e não para destruir a floresta. Para isto, é preciso informar bem a opinião pública (AMIGOS DA TERRA, 1997, p. 19).

Em 1998 o Imaflora firmou parceria com Amigos da Terra e deu novo formato a seu Programa de Apoio à Comercialização de Produtos Certificados, passando a trabalhar com setores produtivos, enquanto à outra ONG couberam as "atividades relacionadas com a divulgação junto aos consumidores finais" (IMAFLORA, 2002, p. 56). Além dessa nova divisão de trabalho, a entidade decidiu realizar um "estudo detalhado do funcionamento do mercado de madeira na região centro-sul do Brasil" (IMAFLORA, 2002, p. 54), agregando para tanto o Imazon, ONG sediada na Amazônia, que dispõe de savoir-faire mais adequado à realização do estudo.

Contudo, o passo mais concreto para impulsionar a construção do grupo ocorreu em outubro de 1999, com a realização em Manaus (AM), do "I Workshop Produção Sustentável de Madeira na Amazônia: oportunidades de negócio". Esse evento, organizado pelo Banco Mundial com o apoio de Imaflora, Imazon, WWF e Amigos da Terra, reuniu, pela primeira vez, os principais atores do mercado de madeiras tropicais (indústria madeireira, indústria compradora de madeira, instituições financeiras (públicas e privadas), governos estaduais da região, governo federal e ONGs) para a discussão de "uma agenda para viabilizar o manejo sustentado e a certificação florestal em larga escala na região" (RELATÓRIO..., 1999, p. 1).

O encontro foi organizado para discutir dois temas: a) a constituição 
ONGs, expertisse e o mercado do desenvolvimento sustentável: a certificação florestal na Amazônia brasileira

do grupo de compradores e b) a atuação conjunta em relação ao problema do financiamento para a indústria madeireira. No que concerne ao tema da certificação e do consumo ${ }^{22}$, duas resoluções foram tomadas, a primeira referente à formação do embrião do grupo de compradores, com a ONG Amigos da Terra assumindo sua coordenação, e a segunda concernente ao aumento da oferta de madeira certificada, com as entidades Imazon e Amigos da Terra estabelecendo como meta a certificação de "2,5 milhões de metros de madeira em tora na Amazônia até o ano de 2005" (RELATÓRIO..., 1999, p. 4).

Como parte da estratégia acertada pelas ONGs da "Aliança para o consumo sustentável", em 1999 foi publicado o estudo Acertando o alvo (SMERALDI; VERÍSSIMO, 1999), que pode ser considerado como um marco na trajetória que levou à constituição do grupo de compradores de madeira certificada. Para tanto, esse trabalho cumpriu duas funções: a) identificou o mercado interno brasileiro (especialmente o de São Paulo) como o principal destino da madeira oriunda da Amazônia e b) esboçou um plano de atuação para a promoção da certificação em determinados segmentos desse mercado.

Ao identificar no mercado interno o principal consumidor da madeira amazônica - com destaque para o papel desempenhado pelo Estado de São Paulo -, o estudo forneceu a justificativa para a atuação de um grupo de compradores no Brasil, pois, como foi destacado no mesmo trabalho, as "estratégias de mercado visando promover o manejo sustentável das florestas [...] podem influenciar concretamente a realidade da exploração, mas apenas na medida em que conseguirem afetar o mercado interno, em particular o Sul e o Sudeste do País" (SMERALDI; VERÍSSIMO, 1999, p. 7).

Quanto ao papel do mercado externo, duas conclusões são avançadas pelo estudo: ele estimularia a produção de madeira certificada para o mercado externo, ao direcionar sua produção de segunda ou terceira categoria para esse mercado, e desempenharia também um papel de indutor, servindo de estímulo para novos investimentos e para a exploração de novas áreas ou novas espécies (SMERALDI; VERÍSSIMO, 1999, p. 35).

\footnotetext{
${ }^{22}$ Quanto ao tema do crédito, foi formada uma força-tarefa, composta por representantes do Banco Axial, do Banco da Amazônia (BASA), do Banco Nacional de Desenvolvimento Econômico e Social (BNDES), do Ministério do Meio Ambiente (MMA) e do Pro Amazônia (Confederação Nacional da Indústria (CNI) e Serviço Nacional de Aprendizagem Industrial (SENAI)), para propor "aprimoramento dos instrumentos financeiros para a indústria que trabalha com a madeira", na extração ou no processamento de forma certificada (RELATÓRIO..., 1999, p. 5).
} 


\section{Marcelo Sampaio Carneiro}

Em 2001 o mesmo conjunto de entidades que realizou a pesquisa e publicou Acertando o alvo realizou um novo estudo ${ }^{23}$, denominado Acertando o alvo 2, no qual avaliam o potencial para a compra de madeira certificada no mercado de São Paulo (SOBRAL et al., 2002). Por meio desse novo trabalho, as ONGs procuram reforçar a tese da possibilidade da promoção da certificação no mercado interno brasileiro, ponto sobre o qual a introdução ao trabalho é incisiva:

Existe o mito de que o mercado brasileiro de madeiras amazônicas não tem interesse em adquirir produtos florestais certificados. Este levantamento inédito realizado em 2001 no Estado [sic] de São Paulo, [...], revela uma situação surpreendente: há uma demanda para madeira certificada de aproximadamente 20\% (1,2 milhão de metros cúbicos em tora) do volume total consumido no Estado [sic]. (SOBRAL et al., 2002, p. 7).

Contudo, apesar dos prognósticos apontados nos dois trabalhos, vale ressaltar que até hoje o principal estímulo para a certificação de empresas produtoras de madeira na Amazônia vem do mercado externo. Por outro lado, como afirmou recentemente o secretário-executivo da ONG Amigos da Terra, o grupo brasileiro de compradores de madeira certificada (GCMC) é composto essencialmente por empresas consumidoras de produtos oriundos de plantações florestais (SMERALDI, 2003, p. 1), tendo, portanto, pouca incidência sobre o consumo de madeira oriunda de florestas nativas.

Outro fato que contribui para limitar a absorção de madeira certificada pelo mercado interno é, ao contrário do afirmado no trabalho Acertando o alvo 2, a concorrência exercida pelos compradores externos. Na terceira assembléia geral do grupo, essa dimensão concorrencial do mercado externo ${ }^{24}$ foi ressaltada:

${ }^{23}$ Com o apoio financeiro da Agência Alemã de Cooperação Técnica (GTZ) e da Embaixada dos Países Baixos.

${ }^{24}$ Como mostra o caso da Indústria Madeireira Shalom - empresa localizada em São Luís (MA), que fornece portas para o grupo americano Home Depot -, que teve de recorrer a fornecedores bolivianos de madeira certificada para poder honrar seus compromissos com seu principal cliente. Segundo relato do proprietário da Shalom, o alto preço praticado pelos produtores brasileiros inviabiliza a compra no mercado interno: "Em setembro do ano passado, uma empresa me ofereceu madeira nativa certificada por 160 reais o metro cúbico [...]. Em janeiro, quatro meses depois, ele subiu o pedido para 350 dólares" (ARNT, 2001, p. 6). 
ONGs, expertisse e o mercado do desenvolvimento sustentável: a certificação florestal na Amazônia brasileira

Algumas empresas continuam sem acesso à madeira certificada da Amazônia, porém, agora o maior obstáculo passa a ser o alto valor de venda, pois normalmente os preços são firmados em dólar, baseados na demanda externa, o que acaba por inviabilizar a realização de mais negócios (RELATÓRIO..., 2002, p. 2).

Quando nos voltamos para a análise do desenvolvimento interno do grupo de compradores, dois aspectos merecem destaque: a) o crescimento do quadro de associados e b) a sua dependência das ONGs que lhe deram origem, as integrantes da "Aliança para o Consumo Sustentável" ${ }^{25}$.

Desde a sua fundação, em abril de 2000, o grupo de consumidores tem conseguido ampliar o seu quadro de associados. De acordo com os últimos dados disponíveis, setenta entidades participam atualmente do grupo. O segmento com maior presença no grupo é o de "móveis, marcenaria e design", com quase a metade do total de associados (31 de 70), vindo em seguida o da indústria madeireira (11 sócios) e do segmento que produz "pisos, portas e guarnições" (7 sócios). Participam ainda do grupo empresas de outros segmentos do mercado madeireiro (construção civil, por exemplo), órgãos públicos (caso dos governos do Estado do Acre e do Amapá) e entidades de representação do setor florestal.

A maior participação de empresas do segmento de "móveis, marcenaria e design" reflete, como vimos anteriormente, a prioridade conferida pelas ONGs ao trabalho de difusão da certificação. O maior peso desse segmento, bem como o reconhecimento do muito que falta ser feito para difundir o conceito no mercado interno brasileiro são conclusões da última assembléia geral do grupo: "A certificação continua sendo um mercado de nicho específico, normalmente o de móveis e objetos com alto valor agregado pelo design" (RELATÓRIO..., 2002, p. 2).

Apesar do crescimento verificado, o funcionamento do grupo de compradores continua muito dependente da atuação das ONGs da "Aliança para o consumo sustentável". Os exemplos dessa dependência são muitos: a secretaria-executiva do grupo é estatutariamente uma

${ }^{25}$ Vale ressaltar que o grupo de compradores do Brasil é uma das poucas iniciativas da "Rede Global Florestas e Comércio" que não foi liderada pelo WWF. As outras exceções estão localizadas na Holanda e nos Estados Unidos. 
Marcelo Sampaio Carneiro

atribuição da ONG Amigos da Terra, a organização do principal evento do FSC no Brasil - a Feira de Produtos Florestais Certificados - foi assumida majoritariamente como uma realização dessas entidades, que também assumiram a responsabilidade pela resolução do principal problema identificado na III Assembléia Geral do Grupo de Compradores:

O aumento da área certificada foi considerado uma necessidade, tanto pelos produtores presentes, quanto para os compradores. A "Aliança para o consumo sustentável de madeira", formada por Amigos da Terra, Imazon e Imaflora, já está atuando para que isso ocorra. O Imazon está formando o Grupo de Produtores Certificados da Amazônia e também identificando novos produtores que podem, com o apoio da "Aliança", chegar à certificação. Amigos da Terra constituiu o maior banco de dados brasileiro de matéria-prima e produtos certificados, já disponível (RELATÓRIO..., 2002, p. 3).

\section{CONCLUSÃO}

O conjunto de ações acima descritas mostra a centralidade do papel assumido por algumas ONGs no desenvolvimento de atividades de promoção da certificação florestal na Amazônia ${ }^{26}$. Em outro artigo, mostramos como essas atividades vão confluir para a construção social do mercado de madeiras certificadas (CARNEIRO, 2005); aqui, entretanto, gostaríamos de assinalar uma outra dimensão desse processo: o peso crescente que o saber detido por um conjunto restrito de profissionais e instituições (experts) tem tido na afirmação da certificação e de outras políticas florestais na Amazônia contemporânea.

Como vimos, cada uma das iniciativas descritas (elaboração dos padrões de certificação, difusão da tecnologia da exploração florestal de baixo impacto, formação do grupo de compradores de madeira certificada) exige investimentos de uma ou mais das ONGs que assumiram a defesa da certificação como alternativa para o processo de destruição dos recursos florestais na Amazônia brasileira. Esses

\footnotetext{
${ }^{26}$ Outro aspecto que deve ser sublinhado é que a promoção da certificação na Amazônia envolve outras ONGs além das destacadas aqui. É o caso do WWF-Brasil, que tem tido um papel importante na construção do FSC-Brasil e tem também apoiado a certificação de operações de manejo florestal executadas por comunidades.
} 
ONGs, expertisse e o mercado do desenvolvimento sustentável: a certificação florestal na Amazônia brasileira

investimentos, por sua vez, envolvem uma gama diferenciada de ações (marketing, lobby, pressão política, pesquisa), competências profissionais variadas (ecologia, exploração florestal, economia, etc.) e um considerável volume de recursos financeiros.

Para ter acesso a esses recursos, essas ONGs devem desenvolver competências específicas - como nos dois casos aqui apresentados, sobre conhecimento e difusão de uma tecnologia florestal (a exploração de baixo impacto) e sobre o comércio de madeiras tropicais -, a partir das quais elas se posicionam no mercado do conhecimento sobre o desenvolvimento sustentável.

Esse mercado também é um campo de disputas, pois a certificação florestal é um tema que atinge interesses os mais diversos no cenário político nacional e internacional, cujo desenvolvimento mobiliza recursos da cooperação internacional, de agências e bancos multilaterais de desenvolvimento e de fundações ${ }^{27}$ que intervêm nas questões do meio ambiente $^{28}$ (CARNEIRO, 2004; SMOUTS, 2001).

Sobre esse ponto vale a pena citar a explicação fornecida por um ex-diretor da carteira de projetos para o desenvolvimento sustentável da Fundação Ford acerca do reordenamento dos investimentos da fundação na Amazônia:

Sintomático desse esforço é o trabalho da Fundação com programas de certificação para produtos florestais. Em meados da década de 1990, a instituição passou a voltar sua atenção para questões importantes que envolvem o manejo e a comercialização da madeira, um bem de alta escala que produz enorme impacto nos padrões regionais de uso da terra na Amazônia. [...] O foco atual da Fundação no desenvolvimento e na aplicação de padrões para o manejo e a comercialização de recursos madeireiros representa uma mudança estratégica em relação aos esforços anteriores, que se concentravam apenas no desenvolvimento de tecnologias adequadas. Novas políticas públicas, avanços tecnológicos e ações cada vez mais efetivas das ONGs vêm criando oportunidades promissoras para tornar essa transformação uma realidade (ANDERSON,

\footnotetext{
${ }^{27}$ Nessa perspectiva, o debate sobre alternativas para a destruição dos recursos florestais na Amazônia - como no caso recente da questão da oportunidade ou não do estabelecimento de concessões florestais - não pode ser compreendido sem a análise da relação dessas instituições com ONGs e institutos de pesquisa na região.

${ }^{28}$ Como argumentam Dezalay e Garth (2002, p. 108-109) para o campo da expertise econômica e dos direitos humanos, essa forte intervenção de instituições internacionais no mercado da expertise ambiental provoca uma "dolarização" no campo de práticas e de saberes, que até então eram quase cativos de organismos estatais e passam a ser organizados pela mediação dessas instituições, principalmente as de origem norte-americana.
} 
Marcelo Sampaio Carneiro

2002, p. 82-83).

Dessarte, estamos vivendo um momento de forte demanda pela expertise florestal, um momento em que entidades encarregadas de promover o desenvolvimento sustentável ampliam seus investimentos na Amazônia, recorrendo de forma sistemática a experts, na esperança de que eles reforcem suas capacidades, de forma a poderem apresentar estratégias que consigam combinar desenvolvimento e conservação na gestão e utilização dos recursos naturais (KALAORA, 1999, p. 514).

A outra face (indesejada?) desse processo é, como vimos na descrição do processo de elaboração do "Padrão para Manejo de Florestas Amazônicas de Terra Firme" - embora tenha contado com uma maior diversidade de representação de ONGs e movimentos sociais do que o processo similar conduzido pelo Cerflor $^{29}$-, que a participação de segmentos sociais importantes (caso dos trabalhadores florestais e representantes das chamadas populações tradicionais) ficou bastante aquém do que pode ser preconizado como uma participação eqüitativa do stakeholders na elaboração dos padrões do FSC ${ }^{30}$.

Por conseguinte, uma das conseqüências do aumento da expertização na questão florestal (e ambiental) na Amazônia é a crescente perda de influência dos movimentos sociais no debate sobre as alternativas de desenvolvimento para a região, uma vez que os conhecimentos mobilizados por agricultores familiares, seringueiros, trabalhadores do setor florestal não são valorizados no mesmo nível do saber do expert e as entidades de representação desses atores sociais não dispõem do mesmo volume de recursos que as ONGs ambientalistas internacionais ${ }^{31}$ para poder intervir nas discussões em curso.

O que fazer nessas circunstâncias? Seria possível voltar ao "tempo dos primeiros encontros" (WAGNER, 1995, p. 108), quando o debate sobre o desenvolvimento sustentável na Amazônia tinha nos movimentos sociais um de seus principais protagonistas? É possível conciliar expertise com participação social?

Creio que uma passagem do texto introdutório do livro La terre

\footnotetext{
${ }^{29}$ Conforme os dados apresentados no documento do Greenpeace que compara a mobilização para a elaboração dos padrões realizada pelos dois sistemas de certificação existente no Brasil, o FSC e o Cerflor (GREENPEACE-BRASIL, 2003).

${ }^{30}$ Estamos tomando como referência de procedimento eqüitativo aquele tipo de processo que é capaz de favorecer a expressão e a consideração da maior diversidade possível de pontos de vista e que oferece como produto uma medida que é considerada como eqüitativa pelos sujeitos que lhe são relacionados (CALLON; LASCOUMES; BARTHE, 2001, p. 335).

${ }^{31}$ Essa assimetria de recursos é mais pronunciada ainda quando o debate envolve o acesso a conferências e instituições internacionais (POULIGNY, 2001).
} 
ONGS, expertisse e o mercado do desenvolvimento sustentável: a certificação florestal na Amazônia brasileira

outragée: les experts sont formels sintetiza de modo exemplar os desafios impostos àqueles que se interessam pela ampliação efetiva dos debates sobre a questão florestal na Amazônia. Dizem os autores:

"(...) a condição realmente indispensável para reduzir o fosso crescente entre a opinião e os experts é, finalmente, colocar em questão o monopólio da ciência como modo de representação da natureza, substituindo-o por uma pluralidade de culturas possíveis - que vão do conhecimento prático extraído da experiência até representações míticas ou imaginárias, passando pela herança das culturas populares tradicionais (sem esquecer naturalmente o conhecimento científico)" (THEYS; KALAORA, 1992, p. 48). 
Marcelo Sampaio Carneiro

\section{REFERÊNCIAS}

AMIGOS DA TERRA-BRASIL. Programa Amazônia. Garimpagem florestal: relatório atualizado sobre a extração ilegal de madeira na Amazônia brasileira. p. 77. 1997.

ANDERSON, Anthony B. Da produção agrícola ao desenvolvimento sustentável. In: BROOKE, N.; WITOSSHYNSKY, M. (Org.). Os 40 anos da Fundação Ford no Brasil: uma parceria para a mudança social. São Paulo: Edusp; Rio de Janeiro: Fundação Ford, p. 57-94. 2002.

ARNT, Ricardo. Madeira especial. Revista Exame. 2001. Disponível em: < http://www2.uol.com.Br/exame/ed751/rep94.shl> . Acesso em: 20 mar. 2004

BASS, Stephen. La certification des forêts: débat sur les normes. Réseau de Foresterie pour le Développement Rural, [S.l.], n. 23b, 1998.

BLATE, G. M.; PUTZ, F. E.; ZWEEDE, J. C. Nouvelles pratiques de récolte en Amazonie. Actualités des Forêts Tropicales, [S.l.], v. 9, n. 2, p. 89, 2001.

BUCLET, Benjamin. Les expérimentations des ONGs en Amazonie: quel pouvoir pour quelle responsabilité? Lusotopie, [S.1.], p. 263-282, 2002.

BUTEL, F.; TAYLOR, P. Environmental sociology and global environmental change: a critical assessment. In: BENTON, T.; REDCLIFT, M. (Ed.). Social theory and the global environment. London and New York: Routledge, p. 228-255. 1994.

CALLON, M.; LASCOUMES, P.; BARTHE, Y. Agir dans un monde incertain: essai sur la démocratie technique. Paris: Seuil, p. 358. 2001.

CARNEIRO, Marcelo D. S. O dinheiro é verde? A construção social do mercado de madeiras certificadas na Amazônia brasileira. 2004. 270 f. Tese (Doutorado em Sociologia) - Instituto de Filosofia e Ciências Sociais, Universidade Federal do Rio de Janeiro, Rio de Janeiro, 2004.

O dinheiro é verde? A construção social do mercado de madeiras certificadas na Amazônia brasileira. In: ENCONTRO ANUAL DA ANPOCS, 29., 2005, Caxambu. Anais... Caxambu, MG, 2005. 
ONGs, expertisse e o mercado do desenvolvimento sustentável: a certificação florestal na Amazônia brasileira

COCHOY, Franck. Une sociologie du packaging ou l'âne de Buridan face au marché. Paris: PUF, p. 225. 2002.

DEZALAY, Yves; GARTH, Bryant G. La mondialisation des guerres de palais: la restructuration du pouvoir d'État en Amérique latine, entre notables du droit et 'Chicago Boys'. Paris: Seuil, 2002.

DYKSTRA, D.P. \& HEINRICH, R. Forest harvesting and transport: old problems, new solutions. Keynote presentation for Session 14 (Forest Harvesting and Transport) at the World Forestry Congress, Antalya, Turkey, 13-22. October 1997. Proceedings Vol. 3, pp. 171-186. 1997.

DYKSTRA, Dennis P. L'exploitation à faible impact: l'ancien et le nouveau. Actualités des Forêts Tropicales, [S.1.], v. 9, n. 2, p. 3-4, 2001.

DYKSTRA, D. P.; ELIAS. L'EFI se concrétise au Brésil. Actualités des Forêts Tropicales, [S.1.], v. 11, n. 4, p. 3-5, 2003.

FAILLACE, Sandra. Certificação florestal do FSC. Rio de Janeiro: Projeto Brasil Sustentável e Democrático; FASE, p. 68. 2001.

FUNDAÇÃO FLORESTA TROPICAL (FFT). Atuação da Fundação Floresta Tropical no manejo sustentável da floresta Amazônica (1994-1999). Belém, p. 16. 2000.

. Relatório das atividades da Fundação Floresta Tropical no ano de 2000. Belém, p. 19. 2001.

GEREFFI, Gary. The organization of buyer-driven global commodity chains: how U.S. retailers shape overseas production networks. In: GEREFFI, Gary; KORZENIEWICZ, Miguel (Ed.). Comoddity chains and global capitalism. Westport and London: Praeger, p. 95-122. 1994.

GREENPEACE-BRASIL. Cerflor: empresas e governo têm credibilidade para realizar certificação florestal? p. 30. 2003.

HINRICHS, A.; RUSLIM, Y. Mise en oeuvre de l'EFI en Indonésie. Actualités des Forêts Tropicales, [S.1.], v. 9, n. 2, p. 6-7, 2001.

IMAFLORA. Relatório anual. Plano estratégico Imaflora 1998-2000 Fundação Ford. Piracicaba, p. 642002. 
Marcelo Sampaio Carneiro

IMAZON. Relatório anual de atividades 1999-2000. Belém, 2001.

SMERALDI, Roberto; VERÍSSIMO, Adalberto. Acertando o alvo: consumo de madeira no mercado interno e promoção da certificação florestal. São Paulo: Amigos da Terra; Piracicaba: Imaflora; Belém: Imazon, 1999.

SMOUTS, Marie-Claude. Forêts tropicales, jungle internationale: le revers de l'écopolitique mondiale. Paris: Presses de Sciences Po, 2001.

SOBRAL, L.; VERÍSSIMO, A.; LIMA, E.; AZEVEDO, T.; SMERALDI, R. Acertando o alvo 2: consumo de madeira amazônica e certificação florestal no Estado de São Paulo. Belém: Imazon, p. 72. 2002.

SOUZA, André L. L. Desenvolvimento sustentável, manejo florestal e o uso dos recursos madeireiros na Amazônia: desafios, possibilidades e limites. 1999. Tese (Doutorado em Desenvolvimento Sustentável do Trópico Úmido) - Núcleo de Altos Estudos Amazônicos, Universidade Federal do Pará, Belém, 1999.

UHL, C.; BARRETO, P.; VERÍSSIMO, A.; BARROS, A. C.; AMARAL, P.; VIDAL, E.; SOUZA JR., C. Uma abordagem integrada de pesquisa sobre o manejo dos recursos naturais na Amazônia. Belém: Imazon, p. 30. 1997.

VERÍSSIMO, A.; BARRETO, P.; MATOS, M.; TARIFA, R.; UHL, C. Impactos da atividade madeireira e perspectivas para o manejo sustentável da floresta numa velha fronteira da Amazônia: o caso de Paragominas. In: ALMEIDA, O. T. (Org.). A evolução da fronteira amazônica. Imazon: Belém, p. 9-37. 1996.

VIANA, Virgílio. As florestas brasileiras e os desafios do desenvolvimento sustentável: manejo, certificação e políticas públicas apropriadas. 2002. 163 f. Tese de Livre Docência, Escola Superior de Agricultura "Luiz de Queiroz", Piracicaba, 2002.

WAGNER, Alfredo. Movimentos sociais na Amazônia. CESE Debate, [S.l.], ano 5, n. 4, p. 81-116, 1995. 
ONGs, expertisse e o mercado do desenvolvimento sustentável: a certificação florestal na Amazônia brasileira

Anexo A - Definição da exploração florestal de impacto reduzido.

Segundo Dykstra (2001, p. 3), a exploração de impacto reduzido não é um conceito novo na Ciência Florestal, significando tão-somente a transferência para florestas tropicais de técnicas já aplicadas às florestas temperadas. Após análise de cerca de 270 publicações tratando do tema, chegaram à seguinte definição: "A EIR é a execução intensamente planejada e atentamente controlada das operações de colheita florestal com vistas à redução ao mínimo do impacto sobre os povoamentos e os solos florestais, quando do corte seletivo de árvores individuais".Contudo, deve-se ressaltar que a EIR não consiste num modelo fechado, ela deve ser adaptada às diversas formações florestais, levando em consideração "os diferentes tipos de floresta e de indústria, bem como a situação econômica das regiões e os diferentes mercados consumidores" (FFT, 2000, p. 2).Apesar dessa sensibilidade aos contextos regionais, uma EIR aplicada às florestas tropicais deve incluir as seguintes medidas, que são também as constantes no Código Modelo de Práticas Florestais da FAO (DYKSTRA, 2001, p. 3; DYKSTRA; HEINRICH, 1997, p. 186):a) realização de inventário pré-exploratório (100\%) e identificação das árvores;b) planejamento das trilhas de arraste e dos pátios temporários, de forma a tornar mínimos os danos ao solo e aos cursos d'água na área a ser explorada;c) realização do corte de cipós nas áreas em que são abundantes; d) construção das estradas, dos pátios temporários e das trilhas de arraste conforme as diretrizes técnicas e ambientais;e) utilização de técnicas adequadas para o abate das árvores e o corte das toras;f) transporte das toras até as trilhas de arraste previstas;g) utilização de sistemas de arraste que protejam o solo e a vegetação residual do impacto do transporte (em algumas situações, no sudeste da Ásia, as toras são transportadas por helicópteros);h) realização de estudos para avaliação do nível de êxito alcançado na aplicação das diretrizes da EIR (quanto às atividades de colheita e ao desempenho do pessoal envolvido na operação).Contudo, vale destacar, que alguns autores, mesmo reconhecendo a superioridade da EIR sobre os sistemas tradicionais de exploração florestal, questionam sua capacidade para assegurar a manutenção da maior parte das espécies exploradas. 